\title{
Modeling and Dynamic Characteristics Analysis of Blade-Disk Dual-Rotor System
}

\author{
Zhenyong Lu $\mathbb{D}^{1,2}$ Shun Zhong $\mathbb{D}^{2,3}$ Huizheng Chen, ${ }^{1,2}$ Yushu Chen, ${ }^{2,3}$ Jiajie Han, ${ }^{4}$ \\ and Chao Wang ${ }^{4}$ \\ ${ }^{1}$ Institute of Dynamics and Control Science, Shandong Normal University, Jinan 250014, China \\ ${ }^{2}$ Tianjin Key Laboratory of Nonlinear Dynamics and Control, Tianjin 300072, China \\ ${ }^{3}$ Department of Mechanics, Tianjin University, Tianjin 300072, China \\ ${ }^{4}$ Hebei Ruizhao Laser Remanufacturing Technology Stock Co., Ltd., Tangshan 064300, China \\ Correspondence should be addressed to Shun Zhong; shunzhong@tju.edu.cn
}

Received 5 September 2019; Revised 17 December 2019; Accepted 30 December 2019; Published 25 January 2020

Academic Editor: Sing Kiong Nguang

Copyright $\odot 2020$ Zhenyong Lu et al. This is an open access article distributed under the Creative Commons Attribution License, which permits unrestricted use, distribution, and reproduction in any medium, provided the original work is properly cited.

In this paper, a simplified dynamic model of a dual-rotor system coupled with blade disk is built, and the effects of blade parameters of an aircraft engine on the dynamic characteristics of a dual-rotor system are studied. In the methodology, the blade is simplified as a cantilever structure, and the dynamical equations are obtained by the means of a finite element method. The amplitude-frequency response curves and orbits of shaft centre-vibration shape diagram are used to analyze the effects of blade parameters on dynamic characteristics of a dual-rotor system. The results indicate that the properties of the blades have huge impacts on the critical speed and other dynamic characteristics of the system. With an increase of the length of the blade, the second-order critical speed decreases obviously, but the first-order critical speed is almost invariant; this means that the blades attached on the low-pressure compressor do not affect the first-order critical speed of the dual-rotor system. Meanwhile, note that the high-pressure rotor and low-pressure turbine rotor can excite the first-order resonance of the dual-rotor system, while the lowpressure compressor rotor can only excite the second-order resonance, and then the dynamic model of this six-point support dual-rotor system can further be simplified as a relatively independent single-rotor system with one disk and a four-support dualrotor system with dual disks.

\section{Introduction}

As one of the most important components of the aeroengine, the blades, mainly including rotor blades and stator blades, have huge effects on the performance and safety of the whole engine system [1]. Only considering the rotor blades, there are so many different types, like fan rotor blades (lowpressure compressor rotor blades), low-pressure turbine rotor blades, high-pressure compressor rotor blades, and high-pressure turbine rotor blades. Thus, the number of the blades is large. And in normal conditions, the blades work under complex environments, for example, the turbine blades are subjected to high temperatures, the centrifugal load of the fan blades is relatively large, etc. All of these make the research urgent.
Euler-Bernoulli beam and Timoshenko beam assumptions are widely used in the dynamic modeling process of the blades. Using an energetic approach, Lesaffre et al. modeled a flexible fully bladed rotor in the rotating frame, and a full set of flexible blades was modeled by Euler-Bernoulli beams clamped in the disk [2]. The influence of shaft bending on the coupling vibration of a single rotor-blade system was analyzed by $\mathrm{Li}$ et al. [3, 4]. In Li's work, the single rotor system was composed of a continuous flexible shaft and a rigid disk, and the disk was regarded as a mass point and the blade was derived by using the Euler-Bernoulli beam model. As the blade was simplified to a Timoshenko beam, a new mathematical model for calculating the normal rubbing force between blades and a flexible casing with suspended springs was deduced by Li et al. [5]. Ma et al. [6, 7] also 
studied the vibration responses of a rotational shaft-diskblade system with blade-tip rubbing. With the blades being modeled as Euler-Bernoulli beams and the centrifugal stiffening effect being considered, some main resonances of a single rotor-blade system with nonlinear supports were investigated [8]. For the single blade, considering the influence of aerodynamic forces, Zhang et al. [9] simplified the blade into a cantilever beam with thin-wall structure and studied the nonlinear vibration problem of the compressor blades. Zheng et al. [10] simplified the blade into a flexible thin plate and studied the blade vibration frequency.

And for the blade-disk-rotor-support coupling system, many scholars had studied the dynamic modeling of the blade-disk-rotor system earlier. A spring-mass model was developed for a mistuned multistage bladed rotor by Sinha [11], and the algorithm for the reduced-order model was presented. Lu et al. gave a review in modeling and modal reduction of the coupling rotor system in [12]. Ma et al. [13] established a new dynamical model and validated it by the finite element method and experimental practice as well. A finite element modeling of the dual-rotor system was established by Sun et al. [14]; the geometry of the compressor blades and turbine blades was replaced by equivalent ring geometrical structure and was identical to the density and Young's modulus of the relevant disk material. Considering the nonlinear factors introduced by the bearing, Li et al. [15] studied the effect of blade vibration. Chiu et al. $[16,17]$ studied the coupling vibration of the multidisk rotor system with or without groups of blades, respectively. Crawley and Mokadam [18] pointed out that the transverse bending vibration of the rotor system was only coupled with the one nodal diameter mode of the blades, and the pitch motion of the blade was independent to each other [19]. Chun and Lee [20] studied the effects of blade parameters on the coupled vibration of the blade-rotor system. Cao et al. [21] simplified the blade into a cantilever beam structure and deeply studied the dynamic model of the blade-rotor system with the consideration of the factors such as sliding bearing, squeeze film damper, and gyro effect, respectively. The influence of blade parameters on the dynamic characteristics of the system showed that the blade parameters have a significant influence on the bifurcation characteristics of the coupled system, and the blade would change the instability speed of the system.

Scholars had also carried out a lot of research on the blade crack problem [22], like the detuned blade-rotor system coupling vibration problem $[23,24]$ and blade-casing rub problem $[25,26]$. In addition, a large number of studies had been carried out on the blade vibration problem based on finite element software [24].

It can be seen that most of the previous studies have focused on the analysis of the dynamic characteristics of an individual blade or the nonlinear characteristics of a single rotor coupled with a group of blades. The studies on dynamic behaviours of the dual-rotor coupled with groups of blades and the effects of the blades on the dual-rotor system are relatively few. Some simplified dynamic models of the dual-rotor system were built [27-29], which can be well used to investigate the nonlinear response characteristics for aeroengine dual-rotor system. But in these models, the influence of blade parameters was not fully considered. However, the mode shapes and critical speeds of the shaft with a bladed disk are different from those without bladed disk [8]. And in the actual structure, the number of aeroengine blades, especially for the fan blades, is large and the shape of blades is thin and long, which would have a significant influence on the dynamic characteristics of the dualrotor system.

Thus, it is of great engineering significance to study the influence of the parameters of multigroup blades on the dual-rotor system. In this paper, the blade-disk-shaftsupport rotor methodology will be introduced in Section 2. Based on a type of aeroengine, the coupling of the blade-dual-rotor system will be established by a finite element method in Section 3. Considering 3 different working conditions, the amplitude-frequency response curves, the axial trajectory-vibration patterns, and other comparative analysis will be given in Section 4 . Then, a dimensionality reduction method will be proposed in Section 5.

\section{Modeling Method of a Blade-Disk-Shaft- Support System}

By the means of the finite element method, the global coupling system can be meshed into the element model. Here, the rotor system is divided into rigid disks, elastic shaft segments, linear bearing supports, and groups of blades. For an elastic shaft section, depending on its property, it would be considered as a Timoshenko or Euler beam element, whose mass will be concentrated to both ends; for a rigid disk, it will be considered as a lumped mass point, which would be superposed to the corresponding node; for a bearing, it will be represented by a springdamper element; and for a group of blades, it will be simplified into a concentrated mass-spring-damper element further.

2.1. Modeling of the Blade. Based on the basic structure of the engine blades, Figure 1 shows a schematic diagram of a dynamical model of a bladed system. The blades are considered to be elastomeric and evenly distributed over the disk, with a lacing attached at $2 / 3$ point to the blade tip.

For groups of engine blades on the disks, the modeling assumptions are as follows:

(a) Consider that the blades on each disk have same parameters and the blades are rigidly fixed to the disk

(b) Each individual engine blade is simplified to a cantilever beam structure, whose mass is concentrated on the top, and can be further simplified to a single pendulum model

(c) The tension between the engine blades is described by spring-damping model 


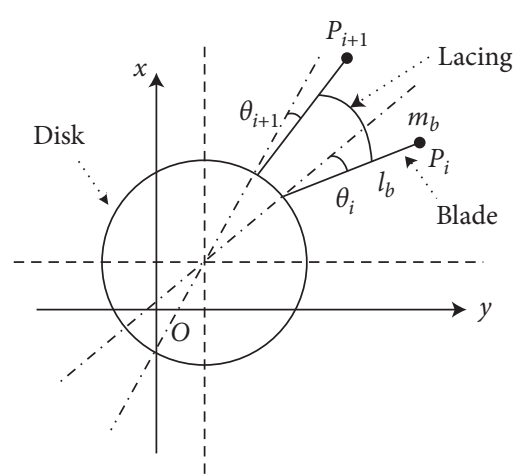

(a)

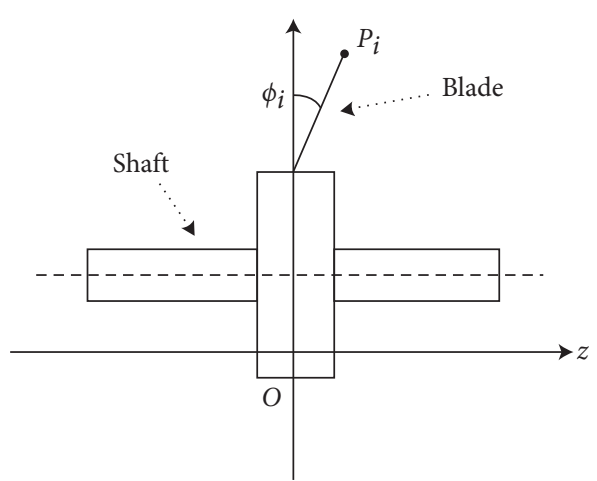

(b)

FIgURE 1: Model of the position of $i$-th blade. (a) In-plane deflection of blade. (b) Out-of-plane deflection.

(d) The blade angle motion is assumed to be small, and the radial displacement and torsion are ignored

(e) Consider that the motion of the $i$-th engine blade is composed of in-plane motion along the circumferential direction of the disk and out-of-plane motion along the axial direction of the rotor [19]

Based on the assumptions above, one of the blades' $\left(P_{i}\right)$ motion can be described as in-plane motion $\theta_{i}$ and out-ofplane motion $\phi_{i}$, which are shown in Figure 1. Besides, the stiffness and the damper of each one blade consist of two parts: (1) the equivalent stiffness and damper of the blade along the rotor axis and the circumferential direction of the disk, which can be represented as $k_{b a}, l^{2} c_{b a}, k_{b p}$, and $l^{2} c_{b p}$; and (2) the equivalent stiffness and damper of the lacing along the rotor axis and the circumferential direction of the disk, which can be represented as $k_{l a}, c_{l a}, k_{l p}$, and $c_{l p}$.

Let the length of the blade be $l_{b}$, section width be $b$, section thickness be $h$, and density be $\rho_{b}$; the mass of one blade equals

$$
m_{b}=\rho_{b} A l_{b}=\rho_{b} b h l_{b} .
$$

The blade model is a cantilever beam structure whose stiffness can be obtained from the first-order natural frequency. The first two natural frequencies of the cantilever beam are

$$
\begin{aligned}
& \omega_{p 1}=\frac{0.56}{l_{b}^{2}} \sqrt{\frac{E_{b} I_{b}}{\rho_{b} A}}, \\
& \omega_{p 2}=\frac{3.51}{l_{b}^{2}} \sqrt{\frac{E_{b} I_{b}}{\rho_{b} A}},
\end{aligned}
$$

where $E_{b}$ is the elastic modulus and $I_{b}$ is the section moment of inertia. Thus, the natural frequency of the pendulum is

$$
\omega_{b}=\sqrt{\frac{k_{b}}{m_{b}}}=\sqrt{\frac{k_{b}}{\rho_{b} A l_{b}}} .
$$

Let $\omega_{b}=\omega_{p 1}$; the equivalent stiffness of the blade is

$$
k_{b}=\frac{0.31 E_{b} I_{b}}{l_{b}^{3}} .
$$

Based on the proportional damper model, the damper of the engine blades could be expressed as

$$
c_{b}=\alpha_{b} m_{b}+\beta_{b} k_{b} .
$$

The proportional coefficients can be obtained by the first two natural frequencies of the engine blades, and then the damper of the engine blades can be obtained.

The lacing could be further simplified to an elongated rod structure which is primarily subjected to tensile forces between the blades. Therefore, the longitudinal stiffness of the lacing can be expressed as

$$
k_{l}=\frac{E_{l} A_{l}}{l},
$$

where $l, E_{l}$, and $A_{l}$ are the length, elastic modulus, and crosssectional area of the lacing, respectively.

Adopting a proportional damper model and letting $m_{l}$ be the mass of the lacing gives the damper of the lacing.

$$
c_{l}=\alpha_{l} m_{l}+\beta_{l} k_{l} .
$$

Taking the Jeffcott rotor as an example, assuming that the disk is described by four degrees of freedom and that $n$ blades are evenly arranged on the disk, the system has $4+2 n$ degrees of freedom, and $8+2 n$ degrees of freedom are considered when two ends are considered. For a rotor system such as an aeroengine, the number of blades per disk is huge, and the DOFs (degrees of freedom) of the coupling system are very high. Considering nonlinear factors, it is difficult to solve. However, according to a large number of literature studies [18-20], the lateral vibration of the rotor system is only coupled with the one pitch diameter motion of the blade and does not couple with others [19]. Du et al. [30] calculated and analyzed the vibration mode of the system.

Let the motion of the blade be expressed as the superposition of each pitch motion 


$$
\begin{aligned}
& l_{b} \theta_{i}=\mu_{0}+\mu_{1 c} \cos \vartheta_{i}+\mu_{1 s} \sin \vartheta_{i}+\mu_{2 c} \cos 2 \vartheta_{i}+\mu_{2 s} \sin 2 \vartheta_{i}+\cdots, \\
& l_{b} \phi_{i}=v_{0}+v_{1 c} \cos \vartheta_{i}+v_{1 s} \sin \vartheta_{i}+v_{2 c} \cos 2 \vartheta_{i}+v_{2 s} \sin 2 \vartheta_{i}+\cdots,
\end{aligned}
$$

where $\mu_{0}$ and $v_{0}$ represent the zero-menstruation motion in the plane of the rotor blade and the out-of-plane direction, respectively; $\mu_{k c}$ and $\mu_{k s}$ represent the $k$-joint motion of the blade in the plane $(k=1,2, \ldots) ; v_{k s}$ and $v_{k c}$ indicate the out of plane $k$-joint movement; and $\vartheta_{i}=2 \pi(i-1) / n$ indicates the position of the $i$-th blade. Based on these, the pitch motion of the rotor blade can be decoupled, and then the equations of the blade-rotor system can be obtained.

2.2. Modeling of the Disk-Shaft-Support System. In this section, the modeling method of the disk-shaft system will be further discussed. Adopting the finite element method of the rotor dynamics [31, 32], the whole linear rotor system can be divided into three parts as rigid disks, an elastic shaft, and bearing supports.

Choosing the $i$-th elastic beam section, its motion can be described by two elements with 8 DOFs as

$$
\begin{aligned}
\mathbf{q} & =\left[x_{i}, y_{i}, \theta_{y i}, \theta_{x i}, x_{i+1}, y_{i+1}, \theta_{y(i+1)}, \theta_{x(i+1)}\right]^{T} \\
& =\left[\mathbf{q}_{i}, \mathbf{q}_{i+1}\right]^{T},
\end{aligned}
$$

where $\mathbf{q}_{i}$ represents the $i$-th node's displacement and rotation angle and $\mathbf{q}_{i+1}$ represents the $(i+1)$-th node's displacement and rotation angle. The detailed description is shown in Figure 2.

For a rigid disk, it will be considered as a lumped mass point superposed to the corresponding node. Then, the governing equation of the node with disk can be written in the form

$$
\mathbf{M}_{d} \ddot{\mathbf{q}}_{d}-\mathbf{G}_{d} \mathbf{q}_{d}=\mathbf{Q}_{d},
$$

where $\mathbf{M}_{d}, \mathbf{G}_{d}$, and $\mathbf{Q}_{d}$ are the equivalent mass, stiffness, and general force of the chosen node.

For a bearing, it will be represented by a spring-damper element. Then, the boundary condition of the corresponding node would be affected.

2.3. The Coupling of the Blades and Disk-Shaft-Bearing Rotor. In the case that $\mathrm{j}$-th node has no blades on it, the governing equations of the seciton can be written in the form

$$
\mathbf{M}_{r}^{j} \ddot{\mathbf{q}}^{e s}-\mathbf{G}_{e s}^{j} \dot{\mathbf{q}}^{e s}+\mathbf{K}_{T}^{e s} \mathbf{q}^{e s}=\mathbf{Q}^{e s}
$$

where $\mathbf{M}_{r}^{j}=\mathbf{M}_{T}^{e s}+\mathbf{M}_{R}^{e s}, \mathbf{G}_{e s}^{j}=\mathbf{G}^{e s} \Omega$, and $\mathbf{K}_{T}^{e s}$ are equivalent mass, damper, and stiffness, respectively, and the explicit expressions of which can be found in Appendix A.

Further, if there are blades attached on the $(i+1)$-th node, let

$$
\mathbf{q}_{b(i+1)}=\left[x_{b(i+1)}, y_{b(i+1)}, \theta_{b y(i+1)}, \theta_{b x(i+1)}\right]^{T},
$$

represent the general motion of the blades, in which $x_{b(i+1)}$ and $y_{b(i+1)}$ represent in-plane motion of the blade and

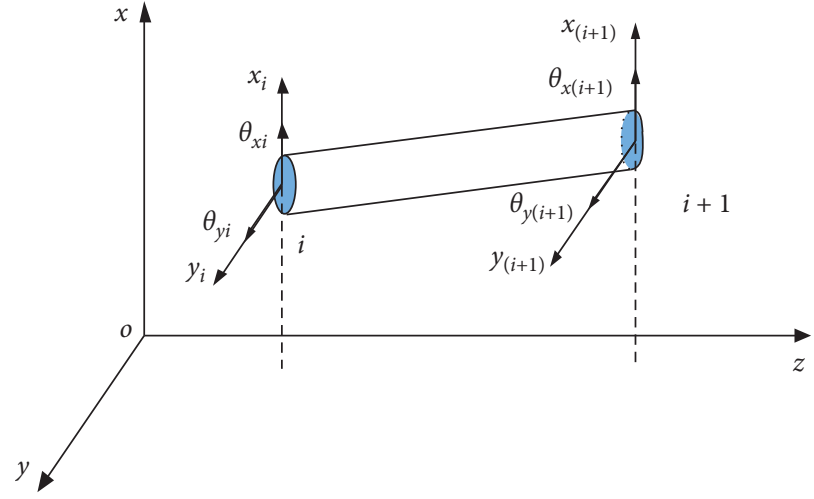

Figure 2: Schematic diagram of an elastic beam section.

$\theta_{b y(i+1)}$ and $\theta_{b x(i+1)}$ represent out-plane motion of the blades, respectively, and

$$
\begin{aligned}
& x_{b(i+1)}=-\mu_{1 s} \cos \Omega t-\mu_{1 c} \sin \Omega t, \\
& y_{b(i+1)}=-\mu_{1 c} \cos \Omega t-\mu_{1 s} \sin \Omega t, \\
& \theta_{b y(i+1)}=\frac{1}{l_{b}}\left(1-v_{1 c} \cos \Omega t+v_{1 s} \sin \Omega t\right), \\
& \theta_{b x(i+1)}=\frac{1}{l_{b}}\left(v_{1 s} \cos \Omega t+v_{1 c} \sin \Omega t\right),
\end{aligned}
$$

gives

$$
\mathbf{M}_{T} \ddot{\mathbf{q}}_{T}-\mathbf{G}_{T} \dot{\mathbf{q}}_{T}+\mathbf{K}_{T} \mathbf{q}_{T}=Q_{T}
$$

where the parameters can be found in Appendix B.

\section{Modeling of a Dual-Rotor System}

Here, based on the analysis and assumptions above, a type of dual-rotor-support coupling system model will be established in this section. A schematic diagram of a dualrotor system of an aircraft engine is shown in Figure 3. The whole system consists of a low-pressure rotor, a highpressure rotor, and six-point supports. The low-pressure compressor blades are very thin and long, the length of which is even longer than the corresponding disk radius, while other blades, such as high-pressure compressor blades, are relatively small compared to the disk (see Figure 1 in reference [29]). So, the effect of the low-pressure compressor blades would be considered most in this section. By the means of the finite element method, the whole coupling system can be discretized into a $14+4$ node dynamic model with 4 groups of blades attached on lowpressure compressor disks and 14 nodes of the shaft-diskbearing model, including two high-pressure disks without blades, one low-pressure turbine disk, and six supports, which are shown in Figure 3 as well.

3.1. The Governing Equations of the Dual-Rotor System. Referring to the aeroengine manual [31, 32], the rotor system model can be divided into rigid disks, elastic shaft segments, 


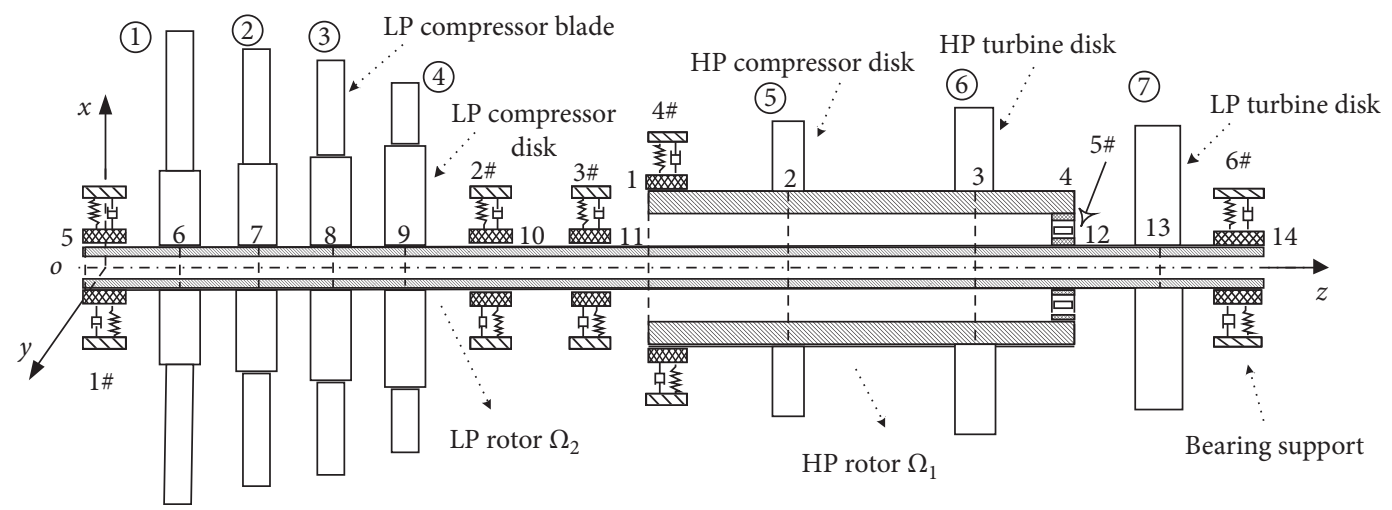

FIGURE 3: Sketch of a blade-dual-rotor-supporting system.

and linear bearing supports (for 1\#-4\# and 6\#, the stiffnesses for $x$-direction and $y$-direction are $2 \times 10^{7} \mathrm{~N} / \mathrm{m}$, and for $5 \#$, the stiffnesses for $x$-direction and $y$-direction are $4 \times 10^{8} \mathrm{~N} / \mathrm{m}$ ), and then the governing equations of the adapted dual-rotor system can be written in the form

$$
\begin{aligned}
& {\left[\begin{array}{ll}
\mathbf{M}_{1} & \\
& \mathbf{M}_{2}
\end{array}\right]\left[\begin{array}{c}
\ddot{\mathbf{q}}_{H} \\
\ddot{\mathbf{q}}_{L}
\end{array}\right]-\left[\begin{array}{ll}
\mathbf{G}_{1} & \\
& \mathbf{G}_{2}
\end{array}\right]\left[\begin{array}{c}
\dot{\mathbf{q}}_{H} \\
\dot{\mathbf{q}}_{L}
\end{array}\right]+\left[\begin{array}{cc}
\mathbf{C}_{1} & \mathbf{C}_{12} \\
\mathbf{C}_{12} & \mathbf{C}_{2}
\end{array}\right]\left[\begin{array}{c}
\dot{\mathbf{q}}_{H} \\
\dot{\mathbf{q}}_{L}
\end{array}\right]} \\
& +\left[\begin{array}{cc}
\mathbf{K}_{1} & \mathbf{K}_{12} \\
\mathbf{K}_{12} & \mathbf{K}_{2}
\end{array}\right]\left[\begin{array}{l}
\mathbf{q}_{H} \\
\mathbf{q}_{L}
\end{array}\right]=\left[\begin{array}{c}
\mathbf{Q}_{H} \\
\mathbf{Q}_{L}
\end{array}\right],
\end{aligned}
$$

in which

$$
\begin{aligned}
\mathbf{q}_{H} & =\left[\mathbf{q}_{1}, \mathbf{q}_{2}, \mathbf{q}_{3}, \mathbf{q}_{4}\right]^{T} ; \\
\mathbf{q}_{L} & =\left[\mathbf{q}_{5}, \mathbf{q}_{6}, \mathbf{q}_{b 6}, \mathbf{q}_{7}, \mathbf{q}_{b 7}, \mathbf{q}_{8}, \mathbf{q}_{b 8}, \mathbf{q}_{9}, \mathbf{q}_{b 9}, \mathbf{q}_{10}, \mathbf{q}_{11}, \mathbf{q}_{12}, \mathbf{q}_{13}, \mathbf{q}_{14}\right]^{T}, \\
\mathbf{Q}_{H} & =\mathbf{F}_{1} \cos \Omega_{1} t+\mathbf{F}_{2} \sin \Omega_{1} t, \\
\mathbf{Q}_{L} & =\mathbf{F}_{3} \cos \Omega_{2} t+\mathbf{F}_{4} \sin \Omega_{2} t,
\end{aligned}
$$

where $\Omega_{1}$ and $\Omega_{2}$ represent the operating speeds of the highpressure rotor and the low-pressure rotor, respectively; $\mathbf{M}_{1}$ and $\mathbf{M}_{2}$ are mass matrices, $\mathbf{G}_{1}$ and $\mathbf{G}_{2}$ are gyration matrices, $\mathbf{C}_{1}$ and $\mathbf{C}_{2}$ are the damper matrices, and $\mathbf{K}_{1}$ and $\mathbf{K}_{2}$ are stiffness matrices of the high-pressure rotor system and the low-pressure rotor system, respectively (including the influence of the blades); and $\mathbf{F}_{1} \cos \Omega_{1} t$ and $\mathbf{F}_{2} \sin \Omega_{1} t$ are unbalanced excitation vectors of the high-pressure rotor and $\mathbf{F}_{3} \cos \Omega_{2} t$ and $\mathbf{F}_{4} \sin \Omega_{2} t$ are the unbalanced excitation vectors of low-pressure rotor, respectively.

3.2. The Validation of the Model. In this section, a validation of the model established in the previous section will be given. A finite element model is established in finite element software as shown in Figure 4. The detailed descriptions are shown below:

(1) The geometry model of dual-rotor is established by solid modeling method, and the finite element model is established by the finite element method

(2) The geometry model of compressor blades and turbine disk blades is established by the method of the equivalent rigid ring

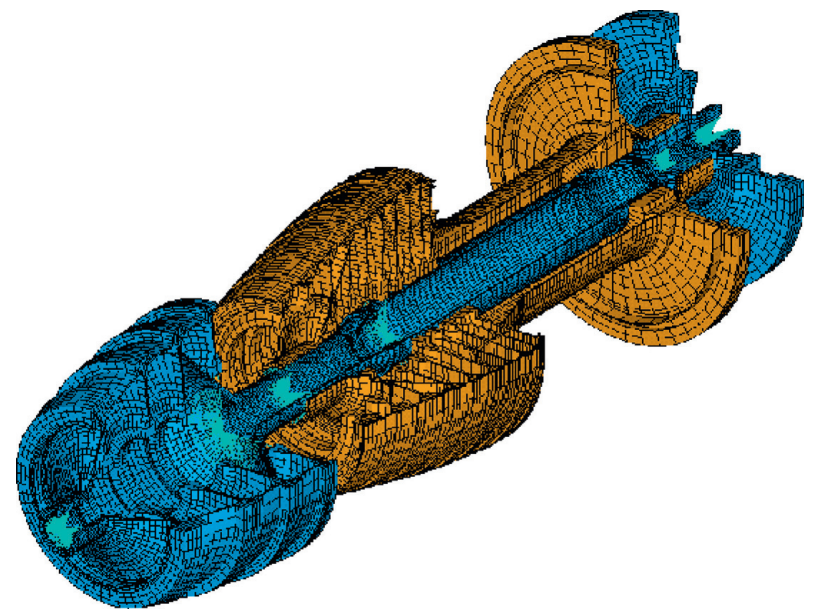

FIgURE 4: A three-dimensional solid finite element model of the dual-rotor system.

(3) Some small features, such as chamfer/fillet, small hole, etc., are ignored

(4) 8-node 6-plane elements are used to mesh the solid model

(5) The bearing centres and disk centres are connected with the corresponding area by rigid massless beams

(6) Combine14 element is used to represent the bearing support

Finally, an element model with total 67,583 elements and 98,083 nodes is built. Among them, there are 30,420 elements and 52,080 nodes for the low-pressure rotor and 36,360 units and 45,990 nodes for the high-pressure rotor. Then, the first two critical speeds are calculated. Compared with the results calculated by the model given in the previous section in case of considering the blades as a concentrated mass, the results are given in Table 1. The errors between the two methods show the model proposed in this paper is reasonable.

\section{Dynamic Characteristics Analysis of the Dual- Rotor System}

As the blades of low-pressure compressor are much longer and thinner than those on high-pressure compressor, 
TABle 1: The comparison of the critical speeds.

\begin{tabular}{lccc}
\hline & $\begin{array}{c}\text { Model proposed in } \\
\text { this paper }\end{array}$ & $\begin{array}{c}\text { Classical finite } \\
\text { element method }\end{array}$ & $\begin{array}{c}\text { Error } \\
(\%)\end{array}$ \\
\hline$\omega_{1}(\mathrm{rad} / \mathrm{s})$ & 701 & 719 & 2.57 \\
$\omega_{2}(\mathrm{rad} / \mathrm{s})$ & 1325 & 1411 & 6.49 \\
\hline
\end{tabular}

which will play a much more important role in the vibration of the system. Let $l=\left[l_{b 1}, l_{b 2}, l_{b 3}, l_{b 4}\right]$ represent the length of blades on four-stage disk and $\Delta l_{b}$ represent the length variation of the blades; we consider three working conditions to investigate the influences on the blades of the system:

Case A: all blades are neglected.

Case B: consider the blades as a concentrated mass at the point of the node.

Case C: consider the parameters of the blades attached to the low-pressure compressor.

Table 2 gives the shaft segment spacing, Table 3 gives the blade parameters, and Table 4 shows the two-stage synchronous forward critical speed of the dual-rotor system with the high-pressure rotor as the main excitation under different working conditions. In Table 4, the critical speeds of working conditions A and B are calculated by the frequency equations, and the critical speed of working condition $\mathrm{C}$ is obtained by the resonant frequency of the amplitude-frequency curve. Comparing the working conditions $\mathrm{A}$ and $\mathrm{B}$, the mass of the blades has an obvious influence on the dynamic characteristics of the dual-rotor system. The critical speed of the system decreases when the mass of blades is added to the system. Comparing the results of working condition $\mathrm{A}$, working condition $\mathrm{B}$, and working condition $\mathrm{C}$, both the blades' mass and the critical speed of the rotor system have effects on the system, but the influence of the mass is dominant. This also shows that the blades can be simplified in the form of concentrated mass to the corresponding node when calculating the critical speed of the system.

Figure 5 shows the amplitude-frequency response curves of the dual-rotor system under operating conditions $\mathrm{A}$ and C. It can be seen that under condition C, the critical speed values are significantly reduced. It is worth mentioning that the high-pressure rotor and the low-pressure turbine rotor resonate only at the first critical speed, while the lowpressure compressor rotor resonates primarily at the second critical speed. This shows that the high-pressure rotor and the low-pressure turbine rotor stimulate the first-order resonance of the dual-rotor system, and the low-pressure compressor rotor provokes the second-order resonance of the dual-rotor system.

Figures 6-8 show the effect of blade length variation on the system's amplitude-frequency curve. It can be seen from the amplitude-frequency curve of the low-pressure compressor rotor in Figure 6 that the second-order critical speed $\omega_{2}$ of the system will decrease when the length of the lowpressure compressor blades increases (1312 rad/s, $1280 \mathrm{rad} / \mathrm{s}$,
TABLE 2: The parameters of the shaft.

\begin{tabular}{lccccc}
\hline & $\begin{array}{c}\text { Nodes } \\
1-4\end{array}$ & $\begin{array}{c}\text { Nodes } \\
5-10\end{array}$ & $\begin{array}{c}\text { Nodes 10 } \\
\text { and 11 }\end{array}$ & $\begin{array}{c}\text { Nodes 11 } \\
\text { and 12 }\end{array}$ & $\begin{array}{c}\text { Nodes 12 } \\
\text { and 13 }\end{array}$ \\
\hline $\begin{array}{l}\text { Length } \\
(\mathrm{m})\end{array}$ & 1.2 & 0.6 & 0.2 & 1.3 & 0.2 \\
\hline
\end{tabular}

TABLE 3: The parameters of the blade.

\begin{tabular}{lc}
\hline Parameters & Value \\
\hline Width & {$[0.0660 .0580 .0510 .048](\mathrm{m})$} \\
Length & {$[0.2660 .1900 .1780 .168](\mathrm{m})$} \\
Thickness & {$[0.00350 .00300 .00250 .022](\mathrm{m})$} \\
Distance & {$[0.05940 .04950 .03890 .0528](\mathrm{m})$} \\
$E_{b}$ & $1.1 * 10^{11}\left(\mathrm{~N} / \mathrm{m}^{2}\right)$ \\
$\rho_{b}$ & $4400\left(\mathrm{~kg} / \mathrm{m}^{3}\right)$ \\
$n_{b}$ & {$[42,50,60,48]$} \\
\hline
\end{tabular}

TABle 4: Synchronous forward critical speeds induced by highpressure rotor (speed ratio equals to 0.8 ).

\begin{tabular}{lcc}
\hline Case & $\omega_{1}(\mathrm{rad} / \mathrm{s})$ & $\omega_{2}(\mathrm{rad} / \mathrm{s})$ \\
\hline Case A & 788 & 1573 \\
Case B & 701 & 1325 \\
Case C & 700 & 1312 \\
\hline
\end{tabular}

and $1248 \mathrm{rad} / \mathrm{s}$ ). From the amplitude-frequency curve of the high-pressure rotor and the low-pressure turbine rotor in Figures 7 and 8 , it can be seen that the first-order critical speed of the system $\omega_{1}$ will decrease when the mass of the high-pressure rotor blade and the low-pressure turbine blade and the parameters of the low-pressure compressor blades are considered. Meanwhile, when the length of the low-pressure compressor blades increases, the value of $\omega_{1}$ does not change. This shows that the length of the lowpressure compressor blades does not affect the first-order critical speed of the system.

\section{Simplification of the Dynamic Model of the Dual-Rotor System}

To further analyze the results from the previous section, Figures 9 and 10 show the three-dimensional axis trajectory map of different node positions of the dual rotor system, that is, the axis trajectory-vibration pattern, when the rotation speed meets the first-order critical speed $\omega_{1}\left(\Omega_{1}=700 \mathrm{rad} / \mathrm{s}\right.$, $\Omega_{2}=560 \mathrm{rad} / \mathrm{s}$ ) and the second-order critical speed $\omega_{2}$ $\left(\Omega_{1}=1640 \mathrm{rad} / \mathrm{s}, \Omega_{2}=1312 \mathrm{rad} / \mathrm{s}\right)$, respectively. It can be seen from Figure 9 that under the first-order critical speed $\omega_{1}$, the axial trajectory of the high-pressure rotor node and the low-pressure turbine node is a large circular shape, which means bending resonance occurs, while the axial trajectory of each node of the low-pressure compressor rotor is relatively small (nonsynchronous), which means resonance does not occur. It can be seen from Figure 10 that, under the second-order critical speed $\omega_{2}$, the axial trajectory 


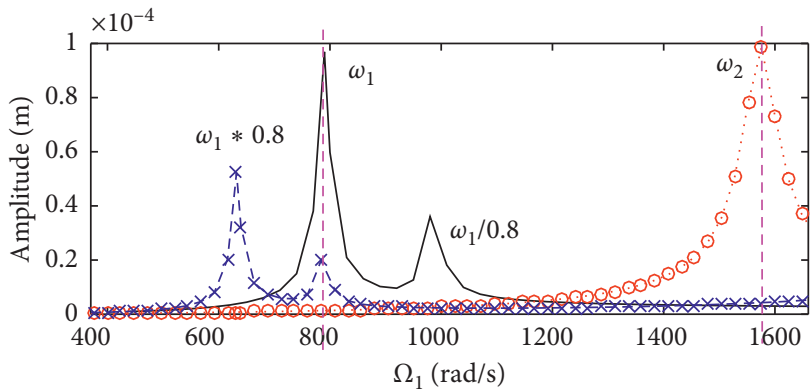

$$
\begin{array}{ll}
- & x_{2} \\
\cdots & x_{7} \\
-*- & x_{13}
\end{array}
$$

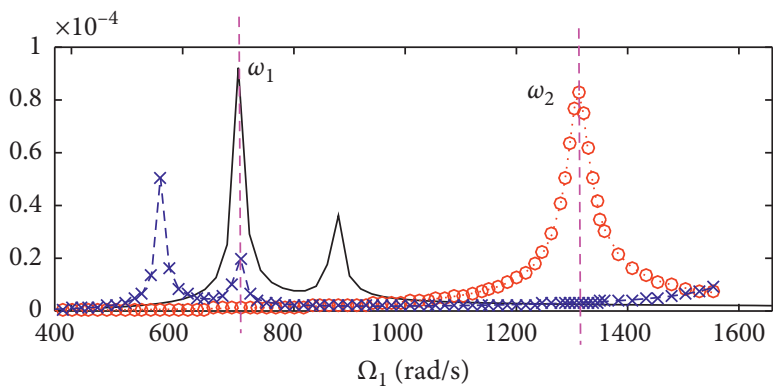

$\begin{aligned}- & x_{2} \\ \cdots & x_{7}\end{aligned}$$$
-*-x_{13}
$$

(a)

(b)

FIGURE 5: Vibration amplitudes versus rotation speeds for the blade-dual-rotor-support system $\left(x_{2}, x_{3}\right.$, and $x_{13}$ represent the displacements of the $x$-direction of the node 2 , node 7 , and node 13). (a) Case A. (b) Case C.

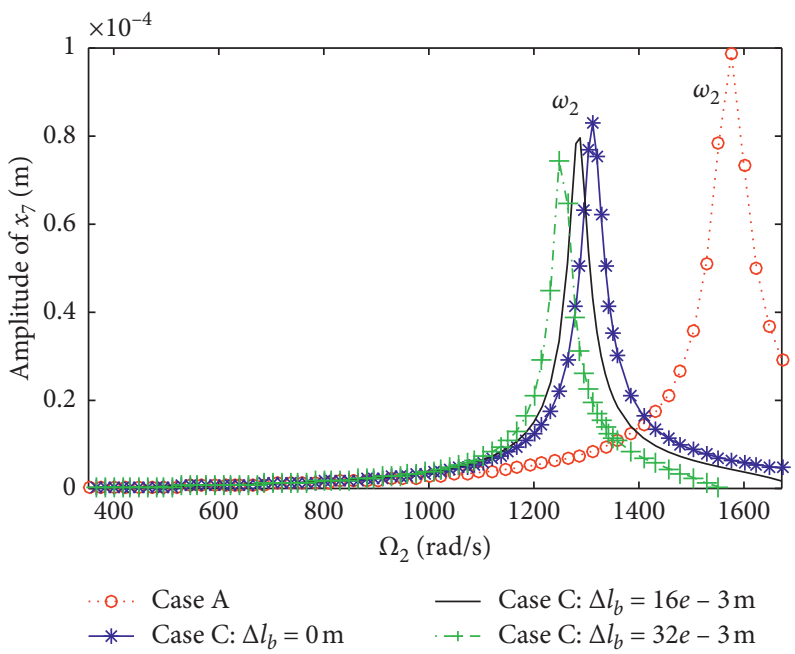

FIgURE 6: Vibration amplitudes of node 7 versus rotation speeds for different $\Delta l_{b}$.

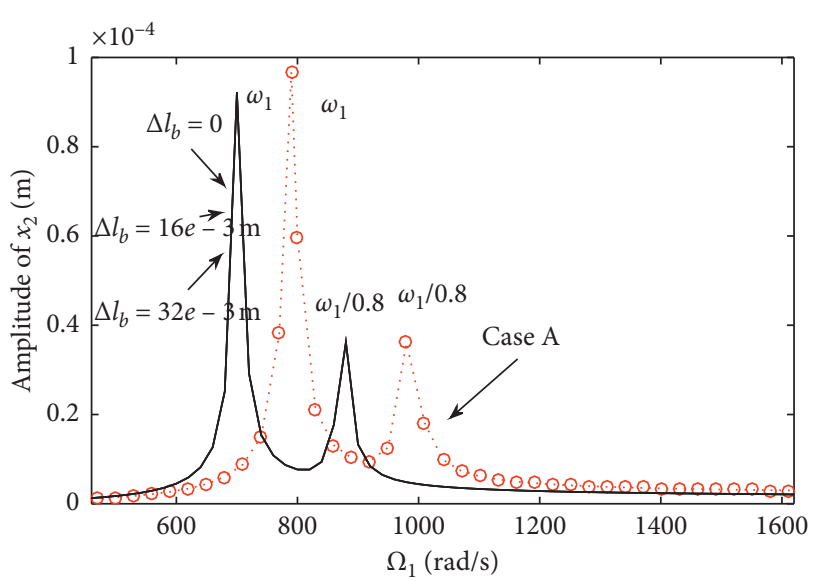

FIGURE 7: Vibration amplitudes of node 2 versus rotation speeds for different $\Delta l_{b}$.

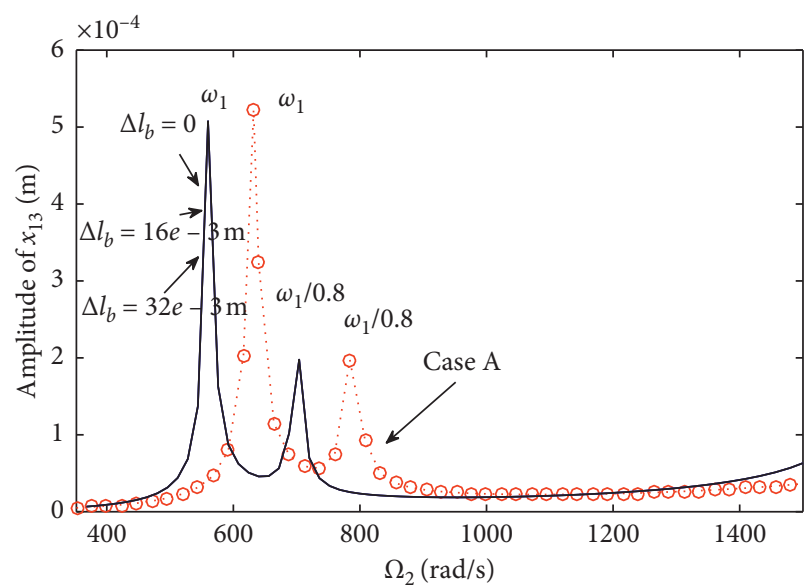

FIGURE 8: Vibration amplitudes of node 13 versus rotation speeds for different $\Delta l_{b}$. 


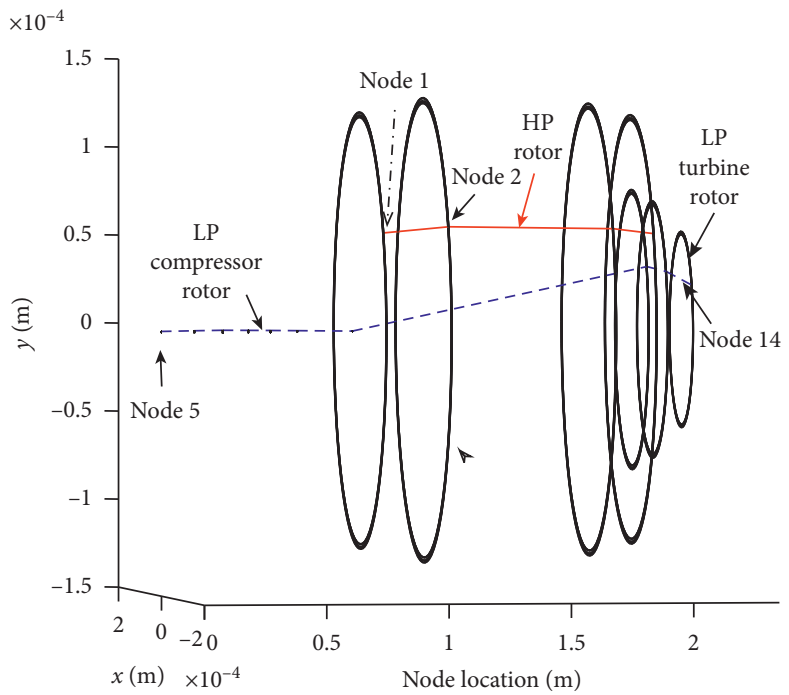

FIGURE 9: Orbits and modal shapes: $\omega_{1}\left(\Omega_{1}=700 \mathrm{rad} / \mathrm{s}, \Omega_{2}=560 \mathrm{rad} / \mathrm{s}\right)$.

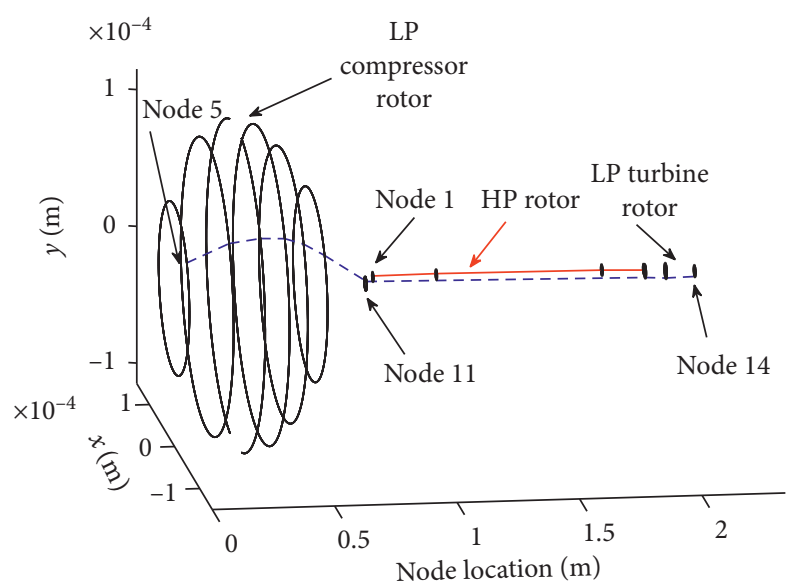

FIGURE 10: Orbits and modal shapes: $\omega_{2}\left(\Omega_{1}=1640 \mathrm{rad} / \mathrm{s}, \Omega_{2}=1312 \mathrm{rad} / \mathrm{s}\right)$.

of each node of the low-pressure compressor rotor is a large circular shape, which means bending resonance occurs, while the trajectory of the nodes of the highpressure rotor and the low-pressure turbine nodes is relatively small, which means (nonsynchronous) resonance does not occur. It also can be seen from Figures 9 and 10 that the high-pressure rotor and the low-pressure turbine rotor provoke the first-order resonance of the dual-rotor system, while the low-pressure compressor rotor provokes the second-order resonance of the dualrotor system. This is because the low-pressure turbine shaft is relatively slender, and the low-pressure compressor rotor system has a low level of vibration coupling with the high-pressure rotor and the low-pressure turbine rotor, which means the low-pressure compressor rotor is relatively "independent." It is worth to note that in the double rotor system of Figure 3, the 2\# and 3\# bearings are normally connected by a flexible coupling, which greatly reduces their coupling level.

From the above results, the low-pressure compressor rotor system can be regarded as a relatively independent single rotor system $A_{1}$, and the high-pressure rotor and the low-pressure turbine rotor can be simplified as a new dualrotor system $B_{1}$, as shown in Figure 11. Under different working conditions, the $A_{1}$ system and the $B_{1}$ system can be analyzed, respectively, as needed.

Furthermore, considering the computational efficiency, when the influence of various complex nonlinear factors on the system are considered, the four-stage roulette in the $A$ system can be simplified to one stage, while the highpressure compressor disk and the turbine disk in the $B$ system could be simplified to one level, so a relatively independent single-rotor system with one disk and foursupport dual-rotor system with dual disks can be obtained (see Figure 12), which has lower degrees of freedom and more practical engineering practice.

To validate our conclusion, we plot the modal diagram of the divided system $A$ and $B$, respectively, and compare with the original system qualitatively as shown in Figures 13 and 14. Figure 13 shows that, with the increase of the rotating speed, when the dual-rotor system(system B) resonates, the single rotor has no 


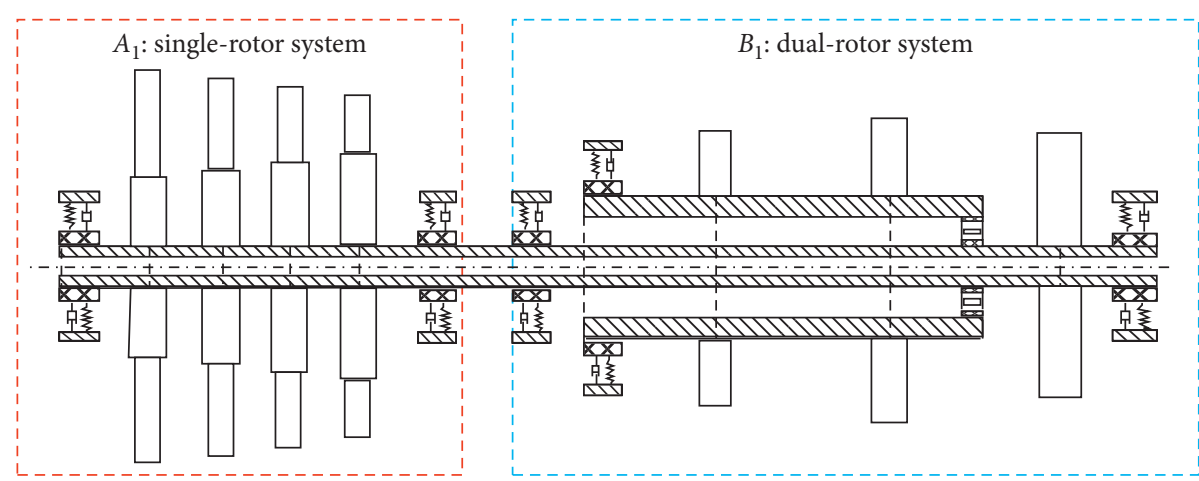

Figure 11: Dynamic model of the dual-rotor system for an aeroengine.

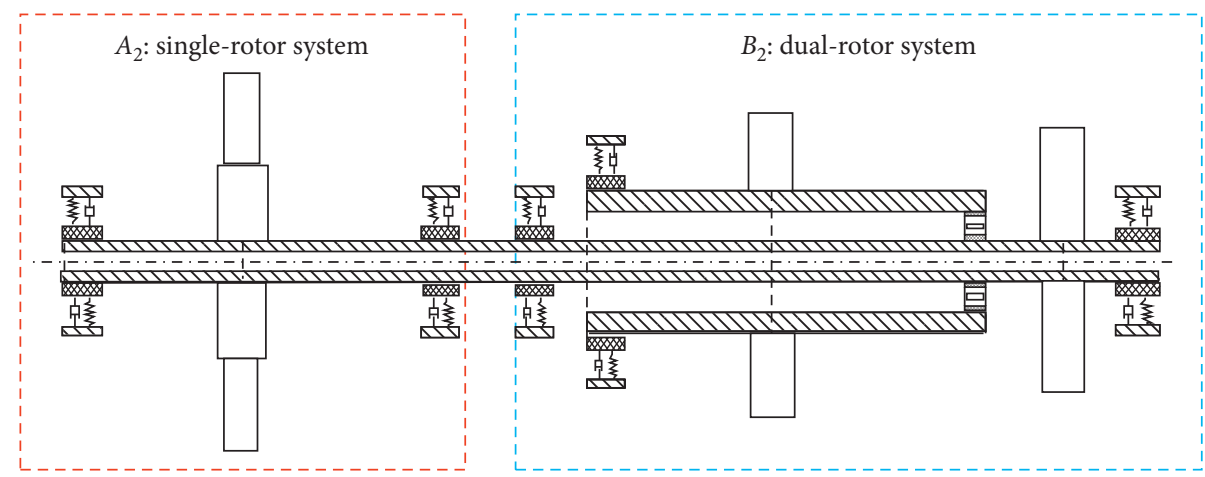

FIGURE 12: A further simplified dynamic model of the dual-rotor system for an aeroengine.

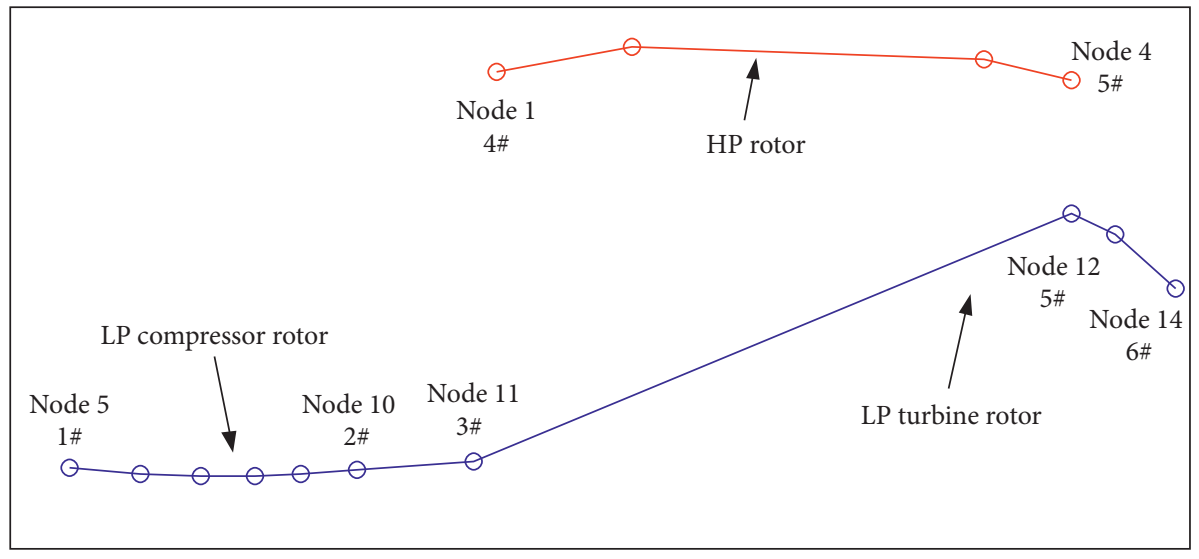

(a)

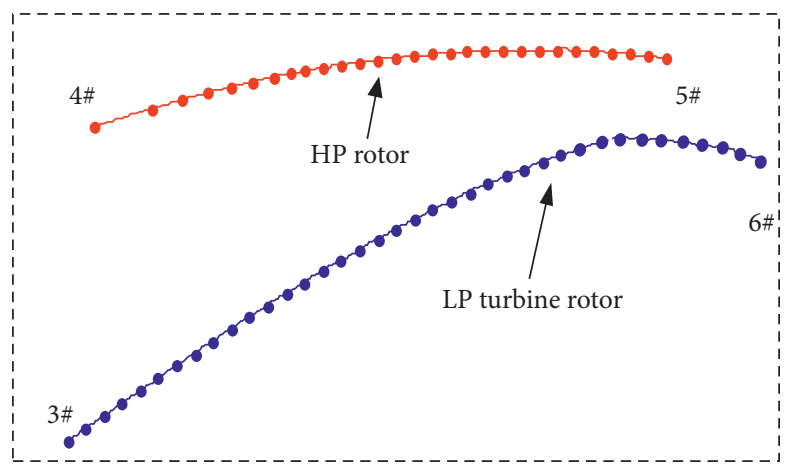

(c)

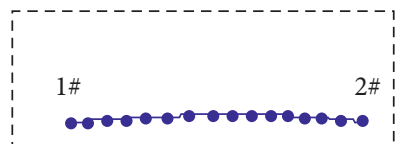

LP compressor rotor

(b)

FIGURE 13: Modal shapes (a) for original dynamical model in Figure 3 at the first critical speed $\omega_{1}$, (b) for separated single-rotor system in Figure 11 at $\omega_{B 1}$, and (c) for separated dual-rotor system in Figure 11 at $\omega_{B 1}\left(\omega_{B 1}\right.$ is the first critical speed for separated dual-rotor system in Figure 11). 


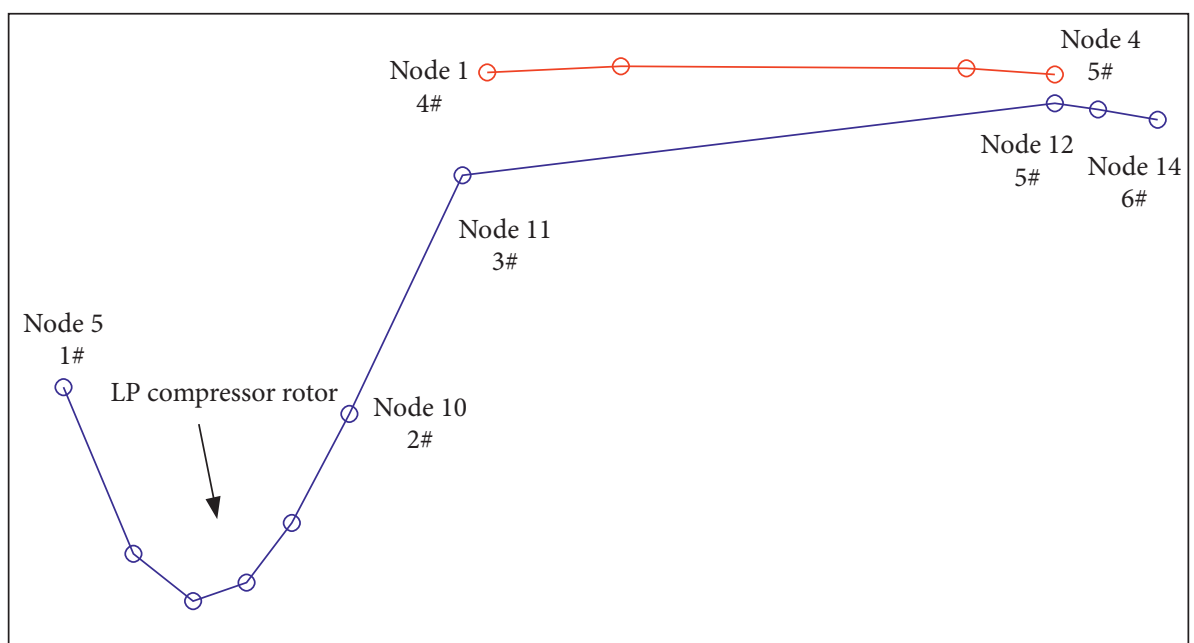

(a)

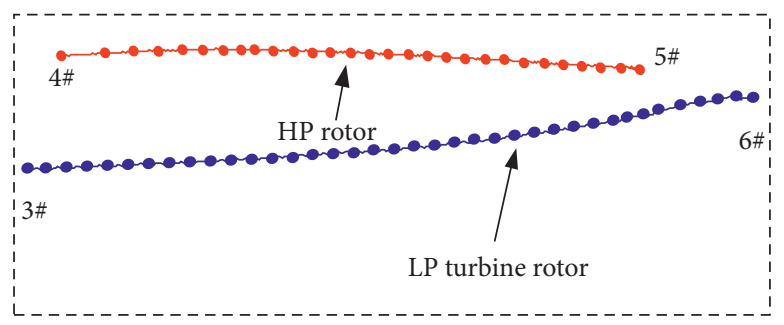

(c)

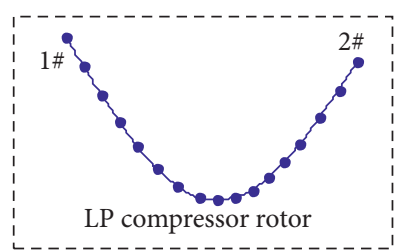

(b)

Figure 14: Modal shapes (a) for original dynamical model in Figure 3 at the second critical speed $\omega_{2}$, (b) for separated single-rotor system in Figure 11 at $\omega_{A 1}$, and (c) for separated dual-rotor system in Figure 11 at $\omega_{A 1}\left(\omega_{A 1}\right.$ is the first critical speed for separated single-rotor system in Figure 11).

resonance. Also, when the single rotor system matches its critical speed, the dual-rotor does not resonate at that rotating speed (shown in Figure 14). It should be noted that it is a qualitative result, and the quantitative result can be matched by equivalently adding the mass to the node 2 (mass of the dual-rotor system) and node 3 (mass of the single-rotor system) and changing the corresponding boundary conditions.

\section{Conclusion}

In this paper, the methodology of the modeling of the dual-rotor coupling with blades and support is proposed based on a type of six point supports aeroengine. The modeling method is verified, and some reasonable results are obtained. With the comparisons of the influences of various conditions and system parameters, a further simplification method is proposed. The main conclusions are as follows:

(1) Blades' stiffness and blades' mass have effects on the critical speed of the dual-rotor system, but the mass influence is dominant, which indicates that the critical speed of the calculation system can be estimated by considering the blade mass as a concentrated mass attached to the corresponding node.

(2) With the increase of the length of the low-pressure compressor blade, the second-order resonance speed $\omega_{2}$ of the system will significantly decrease $(1312 \mathrm{rad} / \mathrm{s}, 1280 \mathrm{rad} / \mathrm{s}$, and $1248 \mathrm{rad} / \mathrm{s}$, respectively); however, the value of $\omega_{1}$ is basically unchanged, which indicates the length of the blades of low-pressure rotor does not affect the first-order critical speed of the six-point support dual-rotor system, and the rotor system can be further simplified.

(3) According to the amplitude-frequency curve diagram and the axial-trajectory-vibration pattern, the highpressure rotor and the low-pressure turbine rotor excite the first-order resonance of the dual-rotor system, and the low-pressure compressor rotor excites the secondorder resonance of the dual-rotor system. Based on this, the six-point-supported dual-rotor system can be further simplified to a relatively independent single-span single-rotor and four-support-dual-rotor dynamic model with low degrees of freedom. 


\section{Appendix}

\section{A. The Detailed Expression of the Mass Matrices and Stiffness Matrices}

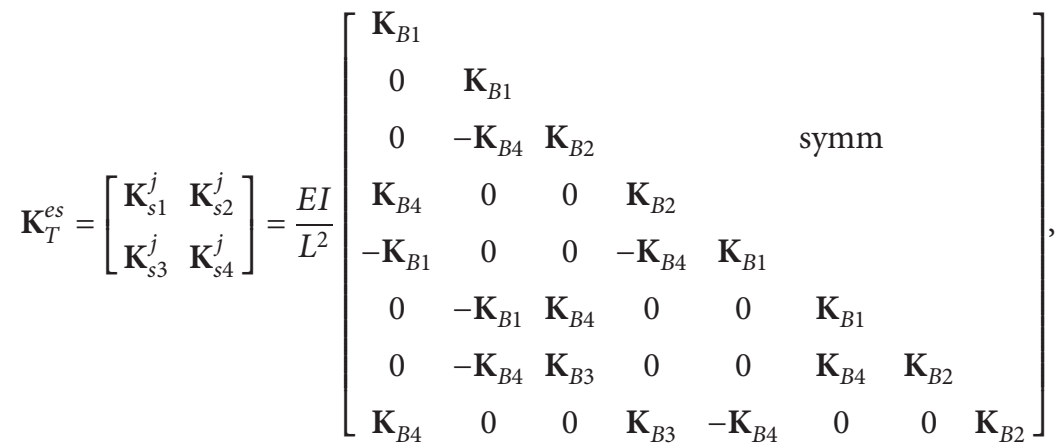

$$
\begin{aligned}
& \mathbf{M}_{T}^{e s}=\left[\begin{array}{ll}
\mathbf{M}_{c 1}^{j} & \mathbf{M}_{c 2}^{j} \\
\mathbf{M}_{c 3}^{j} & \mathbf{M}_{c 4}^{j}
\end{array}\right]=\frac{\rho L}{\left(1+\varphi_{s}\right)^{2}}\left[\begin{array}{cccccccc}
\mathbf{M}_{T 1} & & & & & & & \\
0 & \mathbf{M}_{T 1} & & & & & & \\
0 & -\mathbf{M}_{T 4} & \mathbf{M}_{T 2} & \multicolumn{5}{c}{\text { symm }} \\
\mathbf{M}_{T 4} & 0 & 0 & \mathbf{M}_{T 2} & & & & \\
\mathbf{M}_{T 3} & 0 & 0 & \mathbf{M}_{T 5} & \mathbf{M}_{T 1} & & & \\
0 & \mathbf{M}_{T 3} & -\mathbf{M}_{T 5} & 0 & 0 & \mathbf{M}_{T 1} & & \\
0 & \mathbf{M}_{T 5} & \mathbf{M}_{T 6} & 0 & 0 & \mathbf{M}_{T 4} & \mathbf{M}_{T 2} & \\
-\mathbf{M}_{T 5} & 0 & 0 & \mathbf{M}_{T 6} & -\mathbf{M}_{T 4} & 0 & 0 & \mathbf{M}_{T 2}
\end{array}\right] \text {, } \\
& \mathbf{M}_{R}^{e s}=\left[\begin{array}{ll}
\mathbf{M}_{s 1}^{j} & \mathbf{M}_{s 2}^{j} \\
\mathbf{M}_{s 3}^{j} & \mathbf{M}_{s 4}^{j}
\end{array}\right]=\frac{\rho L}{\left(1+\varphi_{s}\right)^{2}}\left(\frac{r_{\rho}}{L}\right)^{2}\left[\begin{array}{ccccccccc}
\mathbf{M}_{R 1} & & & & & & & \\
0 & \mathbf{M}_{R 1} & & & & & & \\
0 & -\mathbf{M}_{R 4} & \mathbf{M}_{R 2} & & & \\
\mathbf{M}_{R 4} & 0 & 0 & \mathbf{M}_{R 2} & & & & \\
-\mathbf{M}_{R 1} & 0 & 0 & -\mathbf{M}_{R 4} & \mathbf{M}_{R 1} & & & \\
0 & -\mathbf{M}_{R 3} & \mathbf{M}_{R 4} & 0 & 0 & \mathbf{M}_{R 1} & & \\
0 & -\mathbf{M}_{R 4} & \mathbf{M}_{R 3} & 0 & 0 & \mathbf{M}_{R 4} & \mathbf{M}_{R 2} & \\
\mathbf{M}_{R 4} & 0 & 0 & \mathbf{M}_{R 3} & -\mathbf{M}_{R 4} & 0 & 0 & \mathbf{M}_{R 2}
\end{array}\right] \text {, } \\
& \mathbf{G}^{e s}=\left[\begin{array}{ll}
\mathbf{G}_{s 1}^{j} & \mathbf{G}_{s 2}^{j} \\
\mathbf{G}_{s 3}^{j} & \mathbf{G}_{s 4}^{j}
\end{array}\right]=\frac{\rho r_{\rho}^{2}}{15 L\left(1+\varphi_{s}\right)^{2}}\left[\begin{array}{ccccccccc}
0 & & & & & & & \\
\mathbf{G}_{1} & 0 & & & & & \\
-\mathbf{G}_{2} & 0 & 0 & \multicolumn{1}{c}{\text { antisymm }} & \\
0 & -\mathbf{G}_{2} & \mathbf{G}_{4} & 0 & & & \\
0 & \mathbf{G}_{1} & -\mathbf{G}_{2} & 0 & 0 & & \\
-\mathbf{G}_{1} & 0 & 0 & -\mathbf{G}_{2} & \mathbf{G}_{1} & 0 & \\
-\mathbf{G}_{2} & 0 & 0 & \mathbf{G}_{3} & \mathbf{G}_{2} & 0 & 0 \\
0 & -\mathbf{G}_{2} & -\mathbf{G}_{3} & 0 & 0 & \mathbf{G}_{2} & \mathbf{G}_{4} & 0
\end{array}\right],
\end{aligned}
$$

where $\mathbf{K}_{B 1}=12 /\left(1+\varphi_{s}\right) ; \mathbf{K}_{B 2}=L^{2}\left(4+\varphi_{s}\right) /\left(1+\varphi_{s}\right) ; \mathbf{K}_{B 3}=$ $L^{2}\left(2-\varphi_{s}\right) /\left(1+\varphi_{s}\right) ; \mathbf{K}_{B 4}=6 L /\left(1+\varphi_{s}\right) ; \varphi_{s}=12 E I /\left(\mathbf{G} A L^{2}\right) ;$ $\mathbf{M}_{T 1}=(13 / 35)+\left(7 / 10 \varphi_{s}\right)+\left(1 / 3 \varphi_{s}^{2}\right) ; \quad \mathbf{M}_{T 2}=((1 / 105)+(1 /$ $\left.\left.60 \varphi_{s}\right)+\left(1 / 120 \varphi_{s}^{2}\right)\right) L^{2} ; \quad \mathbf{M}_{T 3}=(9 / 70)+\left(3 / 10 \varphi_{s}\right)+\left(1 / 6 \varphi_{s}^{2}\right) ;$ $\mathbf{M}_{T 4}=\left((11 / 210)+\left(11 / 120 \varphi_{s}\right)+\left(1 / 24 \varphi_{s}^{2}\right)\right) L ; \quad \mathbf{M}_{T 5}=((13 /$ $\left.420)+\left(3 / 40 \varphi_{s}\right)+\left(1 / 24 \varphi_{s}^{2}\right)\right) L$
$\mathbf{M}_{T 6}=-\left((1 / 140)+\left(1 / 60 \varphi_{s}\right)+\left(1 / 120 \varphi_{s}^{2}\right)\right) L^{2} ; \quad r_{\rho}=\sqrt{I^{e} / A} ;$ $\mathbf{M}_{R 1}=(6 / 5) ; \mathbf{M}_{R 2}=\left((2 / 15)+\left(1 / 6 \varphi_{s}\right)+\left(1 / 3 \varphi_{s}^{2}\right)\right) L^{2} ; \mathbf{M}_{R 3}=$ $\left(-(1 / 30)-\left(1 / 6 \varphi_{s}\right)+\left(1 / 6 \varphi_{s}^{2}\right)\right) L^{2} ; \mathbf{M}_{R 4}=\left((1 / 10)-\left(1 / 2 \varphi_{s}\right)\right)$ $L ; \mathbf{G}_{1}=36 ; \mathbf{G}_{2}=3 L-15 L \varphi_{s}$ and $\mathbf{G}_{3}=L^{2}+5 L^{2} \varphi_{s}-15 L^{2} \varphi_{s}^{2}$; and $\mathbf{G}_{4}=4 L^{2}+5 L^{2} \varphi_{s}+10 L^{2} \varphi_{s}^{2}$. 


\section{B. The Detailed Expression of the Mass Matrices and Stiffness Matrices with the consideration of the Rotor Blades}

$$
\begin{aligned}
\mathbf{M}_{T} & =\left[\begin{array}{ccc}
\mathbf{M}_{r 1}^{j} & \mathbf{M}_{r 2}^{j} & 0 \\
\mathbf{M}_{r 3}^{j} & \mathbf{M}_{r 4}^{j}+\mathbf{M}_{r 1}^{j+1}+\mathbf{M}_{d}^{i+1}+\mathbf{M}_{b 1}^{i+1} & \mathbf{M}_{b 2}^{i+1} \\
0 & \mathbf{M}_{b 2}^{i+1} & \mathbf{M}_{b 3}^{i+1}
\end{array}\right], \\
\mathbf{G}_{T} & =\left[\begin{array}{ccc}
\mathbf{G}_{s 1}^{j} & \mathbf{G}_{s 2}^{j} & 0 \\
\mathbf{G}_{s 3}^{j} & \mathbf{G}_{s 4}^{j}+\mathbf{G}_{s 1}^{j+1}+\mathbf{G}_{d}^{i+1}+\mathbf{G}_{b 1}^{i+1} & \mathbf{G}_{b 2}^{i+1} \\
0 & \mathbf{G}_{b 2}^{i+1} & \mathbf{G}_{b 3}^{i+1}
\end{array}\right], \\
\mathbf{K}_{T} & =\left[\begin{array}{ccc}
\mathbf{K}_{s 1}^{j} & \mathbf{K}_{s 2}^{j} & 0 \\
\mathbf{K}_{s 3}^{j} & \mathbf{K}_{s 4}^{j}+\mathbf{K}_{s 2}^{j} & 0 \\
0 & 0 & \mathbf{K}_{b}^{i+1}
\end{array}\right],
\end{aligned}
$$

where

$$
\begin{aligned}
& \mathbf{M}_{b 1}^{i}=\frac{n_{i} m_{b i}}{2}\left[\begin{array}{cccc}
2 & 0 & 0 & 0 \\
0 & 2 & 0 & 0 \\
0 & 0 & \left(r_{d i}+l_{b i}\right)^{2} & 0 \\
0 & 0 & 0 & \left(r_{d i}+l_{b i}\right)^{2}
\end{array}\right], \\
& \mathbf{M}_{b 2}^{i}=\left[\begin{array}{cccc}
\frac{n_{i} m_{b i}}{2} & 0 & 0 & 0 \\
0 & \frac{n_{i} m_{b i}}{2} & 0 & 0 \\
0 & 0 & J_{M i} & 0 \\
0 & 0 & 0 & J_{M i}
\end{array}\right] \text {, } \\
& \mathbf{M}_{b 3}^{i}=\frac{n_{i} m_{b i}}{2}\left[\begin{array}{cccc}
1 & 0 & 0 & 0 \\
0 & 1 & 0 & 0 \\
0 & 0 & l_{b i}^{2} & 0 \\
0 & 0 & 0 & l_{b i}^{2}
\end{array}\right] \text {, } \\
& \mathbf{K}_{b}^{i}=\frac{n_{i} m_{b i}}{2}\left[\begin{array}{cccc}
k_{1, B}^{i} & c_{1, B}^{i} \Omega_{i} & 0 & 0 \\
-c_{1, B}^{i} \Omega_{i} & k_{1, B}^{i} & 0 & 0 \\
0 & 0 & l_{b i}^{2} k_{2, B}^{i} & l_{b i}^{2} c_{1, B}^{i} \Omega_{i} \\
0 & 0 & -l_{b i}^{2} c_{1, B}^{i} \Omega_{i} & l_{b i}^{2} k_{2, B}^{i}
\end{array}\right] \text {, } \\
& \mathbf{G}_{b 1}^{i}=\left[\begin{array}{cccc}
0 & 0 & 0 & 0 \\
0 & 0 & 0 & 0 \\
0 & 0 & 0 & -n_{i} m_{b i}\left(r_{d i}+l_{b i}\right)^{2} \Omega_{i} \\
0 & 0 & n_{i} m_{b i}\left(r_{d i}+l_{b i}\right)^{2} \Omega_{i} & 0
\end{array}\right] \text {, } \\
& \mathbf{G}_{b 2}^{i}=\left[\begin{array}{cccc}
0 & 0 & 0 & 0 \\
0 & 0 & 0 & 0 \\
0 & 0 & 0 & -2 J_{M i} \Omega_{i} \\
0 & 0 & 2 J_{M i} \Omega_{i} & 0
\end{array}\right] \text {, } \\
& \mathbf{G}_{b 3}^{i}=\frac{n_{i} m_{b i}}{2}\left[\begin{array}{cccc}
c_{1, B}^{i} & 2 & 0 & 0 \\
-2 & c_{1, B}^{i} & 0 & 0 \\
0 & 0 & l_{b i}^{2} c_{2, B}^{i} & 2 l_{b i}^{2} \\
0 & 0 & -2 l_{b i}^{2} & l_{b i}^{2} c_{2, B}^{i}
\end{array}\right] \text {, }
\end{aligned}
$$

where

$$
\begin{aligned}
& J_{M i}=\frac{n_{i} m_{b i} l_{b i}^{2}}{2}\left(1+\delta_{i}\right), \\
& c_{1, B}^{i}=\frac{1}{m_{b i}}\left[c_{b p}^{i}+2 c_{l p}^{i}\left(1-\cos \Delta \vartheta_{i}\right],\right. \\
& c_{2, B}^{i}=\frac{1}{m_{b i}}\left[c_{b a}^{i}+2 c_{l a}^{i}\left(1-\cos \Delta \vartheta_{i}\right] .\right.
\end{aligned}
$$

\section{Data Availability}

The data used to support the findings of the study are available from the corresponding author upon request.

\section{Conflicts of Interest}

The authors declare that they have no conflicts of interest.

\section{Acknowledgments}

The authors would like to thank Dr Sun Chuanzong for his useful help during the work. This study was supported by the Natural Science Foundation of Shandong Province (grant nos. ZR2018QA005 and ZR2018BA021), National Natural Science Foundation of China (grant nos. 11502161 and 11902184), National Science and Technology Major Project (2017-IV-0008-0045), and Shandong Normal University Youth Science and Technology Project Development Fund.

\section{References}

[1] C. Guang, Structure Design and Analysis of Aero-Engine, Beihang University Press, Beijing, China, 2014.

[2] N. Lesaffre, J.-J. Sinou, and F. Thouverez, "Model and stability analysis of a flexible bladed rotor," International Journal of Rotating Machinery, vol. 2006, Article ID 63756, 16 pages, 2006.

[3] C.-f. Li, H.-x. She, W. Liu, and B.-c. Wen, "The influence of shaft's bending on the coupling vibration of a flexible bladerotor system," Mathematical Problems in Engineering, vol. 2017, Article ID 7313956, 19 pages, 2017.

[4] H. She, C. Li, Q. Tang, and B. Wen, "The investigation of the coupled vibration in a flexible-disk blades system considering the influence of shaft bending vibration," Mechanical Systems and Signal Processing, vol. 111, pp. 545-569, 2018.

[5] B. Li, H. Ma, J. Zeng, X. Guo, and B. Wen, "Rotating bladecasing rubbing simulation considering casing flexibility," International Journal of Mechanical Sciences, vol. 148, pp. 118-134, 2018.

[6] H. Ma, Y. Lu, Z. Wu, X. Tai, and B. Wen, "Vibration response analysis of a rotational shaft-disk-blade system with blade-tip rubbing," International Journal of Mechanical Sciences, vol. 107, pp. 110-125, 2016.

[7] H. Ma, F. Yin, Z. Wu, X. Tai, and B. Wen, "Nonlinear vibration response analysis of a rotor-blade system with bladetip rubbing," Nonlinear Dynamics, vol. 84, no. 3, pp. 12251258, 2016.

[8] B. Li, H. Ma, X. Yu, J. Zeng, X. Guo, and B. Wen, "Nonlinear vibration and dynamic stability analysis of rotor-blade system 
with nonlinear supports," Archive of Applied Mechanics, vol. 89, no. 7, pp. 1375-1402, 2019.

[9] W. Zhang, X. Guo, and Z. Feng, "Analysis on nonlinear dynamics of the aero-engine compressor blade," Scientia Sinica Physica, Mechanica \& Astronomica, vol. 43, no. 4, pp. 345-362, 2013.

[10] T. Zheng, D. Zhang, L. Liao et al., "Rigid-flexible coupling dynamic analysis of aero-engine Blades," Journal of $\mathrm{Me}$ chanical Engineering, vol. 50, no. 23, pp. 42-49, 2014.

[11] A. Sinha, "Reduced-order model of a mistuned multi-stage bladed rotor," in Proceedings of the ASME Turbo Expo 2007: Power for Land, Sea, and Air, pp. 315-322, American Society of Mechanical Engineers (ASME), Montreal, Canada, May 2007.

[12] K. Lu, Y. Jin, Y. Chen et al., "Review for order reduction based on proper orthogonal decomposition and outlooks of applications in mechanical systems," Mechanical Systems and Signal Processing, vol. 123, pp. 264-297, 2019.

[13] H. Ma, Y. Lu, Z. Wu, X. Tai, H. Li, and B. Wen, "A new dynamic model of rotor-blade systems," Journal of Sound and Vibration, vol. 357, pp. 168-194, 2015.

[14] C. Sun, Y. Chen, and L. Hou, "Nonlinear dynamical behaviors of a complicated dual-rotor aero-engine with rub-impact," Archive of Applied Mechanics, vol. 88, no. 8, pp. 1305-1324, 2018.

[15] C. Li, H. She, Q. Tang, and B. Wen, "The effect of blade vibration on the nonlinear characteristics of rotor-bearing system supported by nonlinear suspension," Nonlinear Dynamics, vol. 89, no. 2, pp. 987-1010, 2017.

[16] Y.-J. Chiu and D.-Z. Chen, "The coupled vibration in a rotating multi-disk rotor system," International Journal of Mechanical Sciences, vol. 53, no. 1, pp. 1-10, 2011.

[17] Y. Chiu and C.-H. Yang, "The coupled vibration in a rotating multi-disk rotor system with grouped blades," Journal of Mechanical Science and Technology, vol. 28, no. 5, pp. 16531662, 2014.

[18] E. F. Crawley and D. R. Mokadam, "Stagger angle dependence of inertial and elastic coupling in bladed disks," Journal of Vibration and Acoustics, vol. 106, no. 2, pp. 181-188, 1984.

[19] L. Wang, D. Q. Cao, and W. Huang, "Nonlinear coupled dynamics of flexible blade-rotor-bearing systems," Tribology International, vol. 43, no. 4, pp. 759-778, 2010.

[20] S.-B. Chun and C.-W. Lee, "Vibration analysis of shaft-bladed disk system by using substructure synthesis and assumed modes method," Journal of Sound and Vibration, vol. 189, no. 5, pp. 587-608, 1996.

[21] D. Cao, L. Wang, Y. Chen, and W. Huang, "Bifurcation and chaos of the bladed overhang rotor system with squeeze film dampers," Science in China Series E: Technological Sciences, vol. 52, no. 3, pp. 709-720, 2010.

[22] W. Cui and J. Wang, "Frequency veering and mode shape interaction for a cracked blade," Journal of Propulsion Technology, vol. 36, no. 4, pp. 614-621, 2015, in Chinese.

[23] C. Li, H. She, Q. Tang, and B. Wen, "The coupling vibration characteristics of a flexible shaft-disk-blades system with mistuned features," Applied Mathematical Modelling, vol. 67, pp. 557-572, 2019.

[24] C. Li, S. Zhou, X. Ren, and B. Wen, "Dynamic characteristics of blades-disk-shaft rotor system with mistuned features," Journal of Aerospace Power, vol. 30, no. 1, pp. 67-75, 2015, in Chinese.

[25] L. Hou, H. Chen, Y. Chen, K. Lu, and Z. Liu, "Bifurcation and stability analysis of a nonlinear rotor system subjected to constant excitation and rub-impact," Mechanical Systems and Signal Processing, vol. 125, pp. 65-78, 2019.

[26] Y. Yang, H. Ouyang, X. Wu, Y. Jin, Y. Yang, and D. Cao, "Bending-torsional coupled vibration of a rotor-bearingsystem due to blade-casing rub in presence of non-uniform initial gap," Mechanism and Machine Theory, vol. 140, pp. 170-193, 2019.

[27] L. Hou, Y. Chen, Y. Fu, H. Chen, Z. Lu, and Z. Liu, “Application of the HB-AFT method to the primary resonance analysis of a dual-rotor system," Nonlinear Dynamics, vol. 88, no. 4, pp. 2531-2551, 2017.

[28] Z. Lu, L. Hou, Y. Chen, and C. Sun, "Nonlinear response analysis for a dual-rotor system with a breathing transverse crack in the hollow shaft," Nonlinear Dynamics, vol. 83, no. 12, pp. 169-185, 2016.

[29] Z. Lu, X. Wang, L. Hou, Y. Chen, and X. Liu, "Nonlinear response analysis for an aero engine dual-rotor system coupled by the inter-shaft bearing," Archive of Applied Mechanics, vol. 89, no. 7, pp. 1275-1288, 2019.

[30] X. Du, Z. Xu, and B. Hu, "Whole structure model for calculating vibratory characteristics of continuous cover blades," Turbine Technology, vol. 46, no. 6, pp. 418-420, 2004, in Chinese.

[31] H.-W. D. Chiang, C.-N. Hsu, and S.-H. Tu, "Rotor-bearing analysis for turbomachinery single- and dual-rotor systems," Journal of Propulsion and Power, vol. 20, no. 6, pp. 1096-1104, 2004.

[32] Aero-Engine Design Manual Compiling Committee, AeroEngine Design Manual 19th Part: Rotor Dynamics and WholeEngine Vibration, Aviation Industry Press, Beijing, China, 2000. 